\title{
Mechanical and Post-Cracking Characteristics of Fiber Reinforced Concrete Containing Copper-Coated Steel and PVA Fibers in $100 \%$ Cement and Fly Ash Concrete
}

\author{
Asif Jalal ${ }^{1}$ (D), Luqmanul Hakim ${ }^{2}$ and Nasir Shafiq ${ }^{2, *(D)}$ \\ 1 Department of Civil Engineering, University of Colorado, Denver, CO 80309, USA; asifjalal24@gmail.com \\ 2 Department of Civil Engineering, Universiti Teknologi PETRONAS, Seri Iskandar 32610, Malaysia; \\ hakim.shafiee@petronas.com \\ * Correspondence: nasirshafiq@utp.edu.my
}

Citation: Jalal, A.; Hakim, L.; Shafiq, N. Mechanical and Post-Cracking Characteristics of Fiber Reinforced Concrete Containing Copper-Coated Steel and PVA Fibers in 100\% Cement and Fly Ash Concrete. Appl. Sci. 2021, 11, 1048. https://doi.org/10.3390/ app11031048

Academic Editor: Chao-Wei Tang

Received: 16 December 2020

Accepted: 13 January 2021

Published: 25 January 202

Publisher's Note: MDPI stays neutral with regard to jurisdictional claims in published maps and institutional affiliations.

Copyright: (c) 2021 by the authors. Licensee MDPI, Basel, Switzerland. This article is an open access article distributed under the terms and conditions of the Creative Commons Attribution (CC BY) license (https:// creativecommons.org/licenses/by/ $4.0 /)$

\begin{abstract}
This experimental study investigated the effects of polyvinyl alcohol (PVA) and coppercoated steel (CCS) on the mechanical properties and the post cracking behavior of fiber reinforced concrete (FRC). In designing high-performance concrete mixes, cement replacement materials are the essential ingredients. Therefore, the research objective was to investigate PVA and CCS fiber's postcracking performance in $100 \%$ cement concrete and concrete with $80 \%$ cement and $20 \%$ fly ash. The fiber content was fixed as a $0.3 \%$ volumetric fraction. CSS fibers required $15 \%$ more superplasticizer to achieve the desired slump of fresh concrete than the PVA fibers. Simultaneously, CCS fibers showed a $10 \%$ higher compressive strength than the concrete made of PVA fibers. Both fibers exhibited a similar effect in developing tensile and flexural strength. PVA fibers showed a value of $47 \mathrm{Gpa}$ of secant modulus, and CCS fibers resulted in $37 \mathrm{Gpa}$ in 100\% cement concrete. In post-cracking behavior, CCS fibers showed better performance than the PVA fibers. The reason for this is that CCS showed 2.3 times the tensile strength of the PVA fibers. In comparing the two concretes, fly ash concrete showed about $10 \%$ higher compressive strength at 56 days and about $6 \%$ higher tensile and flexural strength. Similarly, fly ash concrete showed more than $15 \%$ first crack strength and flexural toughness than the $100 \%$ cement concrete in post-cracking behavior. Fiber-reinforced concrete containing PVA or CCS fibers showed enhanced post-cracking characteristics and its use could be preferred in structural applications.
\end{abstract}

Keywords: fiber-reinforced concrete; fly ash; PVA fibers; ductility index; first-crack strength; copper coated steel fibers

\section{Introduction}

Due to global pressure on achieving sustainability, many industries and disciplines are facing challenges in coping with sustainable development demands. In this regard, the concrete making industry faces enormous challenges because concrete is the second-largest consumable materials on the planet [1]. The demand in terms of sustainability is that concrete should be strong enough to resist load, which can reduce the size of structural members. Concrete can be cast in any desired shape with a low energy profile. In the last few years, successful efforts have been made in achieving the ultra-high strength of concrete by varying the water to cement ratio and by the use of new generation admixtures. Achievement of ultra-high-strength concrete resulted in increased brittleness when subjected to adverse conditions, which is one of its drawbacks regarding its long-term performance [1].

Similarly, high strength concrete showed a less fire-resistant character, which can cause a sudden loss of strength in cases of fire exposure [2]. Therefore, toughness and ductility are the two essential properties of high strength concrete (HSC), representing the requirements for achieving adequate performance, particularly when subjected to abnormal conditions. 
Thus, during the second half of the twentieth century, steel fiber reinforced concrete (SFRC) was introduced. It helped to enhance the ductility and toughness of HSC. Still, it has raised the concern of corrosion of the steel fibers during severe conditions, which may lead to concrete spalling $[3,4]$.

The uniformly distributed discrete fibers' mechanism is to resist the cementitious matrix so that it does not come apart, even after failure. Evenly distributed fibers tend to maintain a link within the cementitious matrix and improve its post-cracking behavior [4] Several studies showed that SFRC exhibited ductile failure under both compression and tensile loading conditions [5]. Additionally, it has increased compressive strength and modulus of rupture [6]. In another study, Song and Hwang [7] reported that steel fibers with different volume fractions improved the compressive strength, split tensile strength, modulus of rupture, and toughness index. It also enhanced the post-crack ductility by providing a bridging effect across the crack. Hence, it increased the energy absorption capability of the matrix [8,9]. Despite the many advantages of steel fibers, they are costly; as an estimate, it was found that a $1 \%$ addition of steel fibers doubled the cost of the concrete composite [8]. To overcome the corrosion issues of steel fibers, they were coated [10], and showed a significant improvement in concrete properties [11].

In the next era of fiber reinforced concrete (FRC), alternative forms of fibers, such as non-metallic fibers, were utilized to overcome the corrosion issues. Commonly investigated non-metallic fibers are polypropylene fibers that increased the toughness and ductility but harmed the mechanical properties of the concrete [12]. In contrast, nylon fibers show relatively better results [13]. Basalt fibers are another alternative type that have been investigated during the last decade. Chopped basalt fibers showed high ductility [14] and much-improved post-cracking behavior in concrete [15]. They formed a firm bond with the cement matrix [16]; however, they caused comparatively worse effects on compressive strength and concrete workability, making them an unfeasible option $[17,18]$. In most research studies on FRC, the concrete's workability was not controlled by increasing the amount of superplasticizer or the water to cement ratio; its hardened concrete properties were appreciably reduced $[19,20]$. Polyvinyl Alcohol (PVA) fibers are a recent introduction in the non-metallic fiber family, and have caused much enhancement in concrete properties. They have increased the compressive, split tensile, and flexure strength of newly introduced Engineered Cementitious Composites (ECC) [21]. Due to the fact that PVA fibers enhance the bridging action and cracking strength [22], they are regarded as an attractive option because of these beneficial effects. Hu et al. [23] investigated $12 \mathrm{~mm}$ long PVA fibers; they found an increase in compressive strength and elastic modulus within a particular fiber dosage limit.

In contrast, split tensile strength was increased by increasing the fiber content. Noushini et al. [24] studied the mechanical and structural properties of $6 \mathrm{~mm}$ and $12 \mathrm{~mm}$ length PVA fiber reinforced concrete. PVA fiber increased tensile and flexure properties with constant compression strength up to 0.25 volume fraction, while PVA fiber also increased ductility in reinforced concrete (RC) beams. Noushini et al. [25] conducted a detailed study on adding PVA fibers to concrete; the research parameters included two different lengths ( $6 \mathrm{~mm}$ and $12 \mathrm{~mm}$ ). Cement replacement by $30 \%$ fly ash maintained the constant slump of concrete. Noushini et al. [25] observed an improvement in the post-cracking response of the fiber-reinforced matrix. They also observed enhanced ductility and higher mechanical properties when fiber content was kept at $0.25 \%$. When the fiber content was increased to $0.375 \%$, they observed declining effects on concrete properties. As discussed above, fiber-reinforced concrete was initially developed to improve the flexural performance of structural members under service conditions. Cao et al. [26] observed that, until recently, most of the researchers were biased towards investigating material parameters of FRC and reducing the cost of the end product. These research studies provided enough data for designing the FRC members for serviceability requirements. However, only a few research studies have focused on the FRC matrix's non-linear behavior, and they mostly studied steel fibers [27]. Zahid et al. [28] have recently published research on the post-cracking 
and fracture behavior of engineered geopolymer concrete using PVA fibers. The novelty of the current work is the detailed investigation of post cracking performance of concrete containing copper coated steel and PVA fibers. Such types of concrete are widely used for large constructions. For example, the developed concrete was used in post-tensioned beams for enhancing the bursting strength at the anchorage edge.

This study aims to investigate the effects of low volume fraction $(0.3 \%)$ of PVA and CCS fibers on the mechanical properties, modulus of elasticity, ductility, and concrete post cracking characteristics. Two sets of concrete are studied, one with $100 \%$ cement and the other with $80 \%$ cement and $20 \%$ fly ash. In comparing PVA and CCS fibers, a $0.3 \%$ volume fraction of fibers was fixed. The fiber aspect ratio was 100 and 90 for CCS and PVA fibers, respectively. The post cracking characteristics included first crack strength; toughness index; $\mathrm{I}_{5}, \mathrm{I}_{10}$, and $\mathrm{I}_{20}$; flexural toughness; and the ductility index.

\section{Materials and Methods}

\subsection{Material Properties}

In this study, cement called Cem-1conforming to ASTM C150 supplied by Lafarge, Malaysia, and Class-F fly ash (ASTM C618-15) from the Manjung Power Station, Perak, Malaysia was used. Well-graded coarse aggregates in sizes ranging from $4.75 \mathrm{~mm}$ to $14 \mathrm{~mm}$, a fineness modulus of 7.23, and a specific gravity of 2.62 were obtained from a nearby quarry in Perak, Malaysia. River sand was supplied as a fine aggregate; its properties were measured as: fineness modulus of 2.2, water absorption of $1 \%$, and specific gravity of 2.55 . Sika Malaysia's Superplasticizer, called Viscocrete 2044, conforming to ASTM C494, was used to improve the concrete's slump. The specifications of the fibers (copper coated steel and PVA) are given in Table 1.

Table 1. Physical and Mechanical Properties of fibers [19].

\begin{tabular}{ccc}
\hline Properties & Copper Coated Steel (CCS) Fiber & PVA Fiber \\
\hline Length $(\mathrm{mm})$ & 20 & 18 \\
Diameter $(\mu \mathrm{m})$ & 200 & 200 \\
Aspect Ratio $(\mathrm{l} / \mathrm{d})$ & 100 & 90 \\
Density $\left(\mathrm{g} / \mathrm{cm}^{3}\right)$ & 7.85 & 1.3 \\
Tensile strength $(\mathrm{MPa})$ & 2300 & 1000 \\
\hline
\end{tabular}

\subsection{Mix Proportion}

In this experimental study, an approach based on trial mix proportioning was adopted to achieve the required strength; however, the trial was based on earlier research studies. The target compressive strength to accomplish at 28 days was set as $70 \pm 5 \mathrm{MPa}$. The workability of fresh concrete was measured using the slump test, targeted between $90-110 \mathrm{~mm}$. Volume fraction and water added to cementitious material ratio was kept constant at 0.4. A dosage of superplasticizer obtained from SIKA Malaysia was added to achieve the desired slump value. Table 2 shows the details of all mixes used in this study. The mixing was done in a 100-L laboratory mixer.

\subsection{Mixing, Casting, and Testing of Specimens}

The casting and curing of concrete were done according to ASTM C192/C192M-16a. The fresh concrete was placed in three layers in the mods. Cube sizes of $100 \times 100 \times 100 \mathrm{~mm}$ were used for the compressive strength test, $100 \times 200 \mathrm{~mm}$ size cylinders were cast for split tensile and elastic modulus, and $100 \times 100 \times 500 \mathrm{~mm}$ prisms were used for the flexural strength test. After mixing each of the concrete mixes in a pan type mixer, its slump was measured according to ASTM C143/C143M-15a before casting into its respective mold. After casting all specimens, they were left in the molds overnight and covered by a black plastic sheet. Overnight and after demolding, all samples were moved to the curing room (at 100\% Relative Humidity) until the time of testing. Concrete cubes for compressive 
strength were tested according to BS EN 12390-3:2009 at 3, 28, and 56 days. The cubes were tested in a $100 \mathrm{kN}$ capacity digital testing machine, as shown in Figure 1a. Concrete prisms were tested for the four-point bending test using a $1000 \mathrm{kN}$ capacity actuator attached to the loading frame, as shown in Figure 2. The purpose was to determine the toughness index and the load-deflection curve. The bending test was conducted at 28 days, according to ASTM C 1018-97. The third test in this study was a split-cylinder tensile test (STT), which was conducted on the same machine used for compressive strength; the test set-up is shown in Figure 1b. STT was done to obtain tensile strength and elastic modulus of the concrete. Elastic modulus was determined using a stress-strain curve acquired during the beam bending test. A $60 \mathrm{~mm}$ long strain gauge was pasted to the sample to measure strain values and was connected to a data logger, conforming to ASTM C469/C469M. Even though the split-cylinder test was done according to ASTM C496/C496M-04, this test was also done at 28 days.

Table 2. Details of concrete mix proportions.

\begin{tabular}{|c|c|c|c|c|c|c|c|c|}
\hline \multirow[b]{2}{*}{ Mix ID } & \multicolumn{2}{|c|}{$\begin{array}{c}\text { Fiber Content (by Volume) } \\
(\%)\end{array}$} & \multirow{2}{*}{$\begin{array}{l}\text { Cement } \\
\left(\mathrm{kg} / \mathrm{m}^{3}\right)\end{array}$} & \multirow{2}{*}{$\begin{array}{l}\text { Fly Ash } \\
\left(\mathrm{kg} / \mathrm{m}^{3}\right)\end{array}$} & \multirow{2}{*}{$\begin{array}{c}\text { Coarse Aggregate } \\
\left(\mathrm{kg} / \mathrm{m}^{3}\right)\end{array}$} & \multirow{2}{*}{$\begin{array}{c}\text { Fine Aggregate } \\
\left(\mathrm{kg} / \mathrm{m}^{3}\right)\end{array}$} & \multirow[b]{2}{*}{ W/C Ratio } & \multirow[b]{2}{*}{ SP (\%) } \\
\hline & $\begin{array}{l}\text { Polyvinyl } \\
\text { Alcohol } \\
\text { (PVA) }\end{array}$ & $\begin{array}{c}\text { Copper } \\
\text { Coated Steel } \\
\text { (CCS) }\end{array}$ & & & & & & \\
\hline $\begin{array}{l}\text { Control Mix } \\
\text { (CM) } \\
\text { Fly Ash }\end{array}$ & 0 & 0 & 425 & 0 & 1100 & 705 & 0.4 & 0.35 \\
\hline $\begin{array}{l}\text { Contro Mix } \\
\text { (CF) }\end{array}$ & 0 & 0 & 340 & 85 & 1100 & 705 & 0.4 & 0.25 \\
\hline P0.3 & 0.3 & 0 & 425 & 0 & 1100 & 705 & 0.4 & 0.3 \\
\hline S0.3 & 0 & 0.3 & 425 & 0 & 1100 & 705 & 0.4 & 0.5 \\
\hline PF0.3 & 0.3 & 0 & 340 & 85 & 1100 & 705 & 0.4 & 0.3 \\
\hline SF0.3 & 0 & 0.3 & 340 & 85 & 1100 & 705 & 0.4 & 0.5 \\
\hline
\end{tabular}

Note: $\mathrm{SP}$ is superplasticizer, and $\mathrm{W} / \mathrm{C}$ is water to cementitious binder ratio.

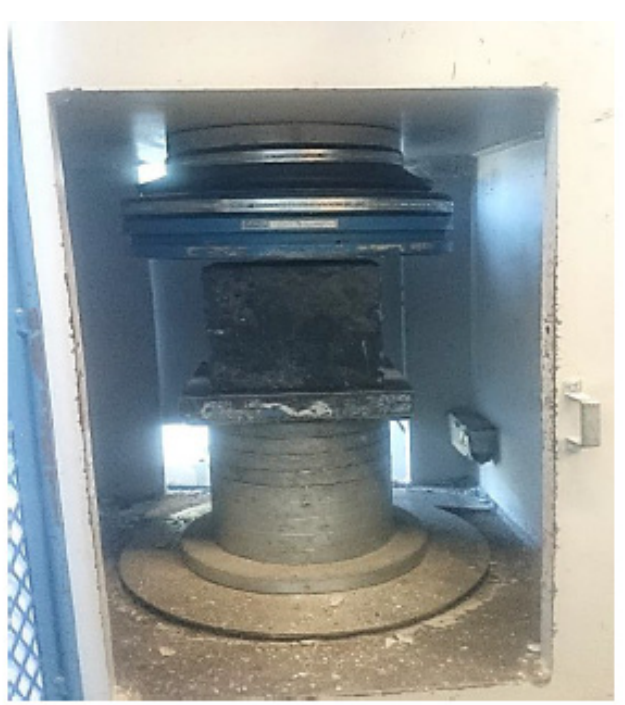

(a)

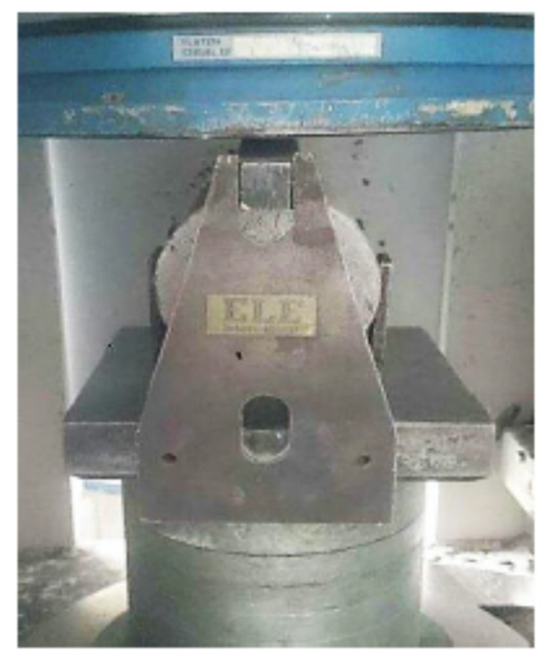

(b)

Figure 1. Concrete Testing (a) Compressive Strength Test (b) Split Tensile Strength Test. 


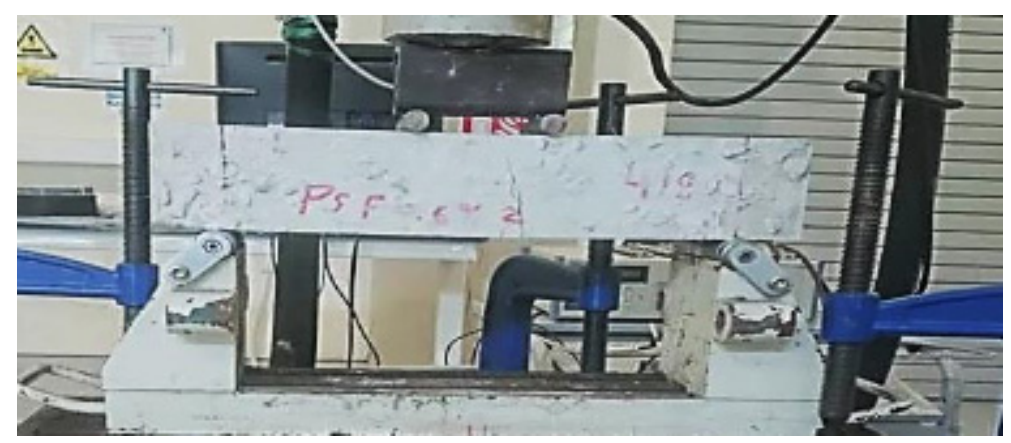

Figure 2. Four-Point Flexural Strength Test.

\subsection{Post-Cracking Characteristics}

ASTM C1018 [29] has discussed the test method for determining the flexural toughness and the fiber-reinforced concrete's first crack strength. The material's flexural toughness is determined by estimating the area under the load-deformation curved obtained during the beam bending test, indicating its energy absorption capacity. Figure 3 shows the typical load-deformation curve of FRC referred to by ASTM C1018 and discussed in the available literature [30-33]. By referring to the Figure 3, the first crack strength or toughness is estimated as the area OAJ, which characterizes the material's toughness at the onset of the first crack. There are three other toughness indices: $\mathrm{I}_{5}, \mathrm{I}_{10}, \mathrm{I}_{20}$, and $\mathrm{I}_{30}$ are calculated at the deflection level of $3 \delta, 5.5 \delta, 10.5 \delta$, and $15.5 \delta$, where $\delta$ is the deflection measured at the onset of the first crack. All these indices are dimensionless numbers, and the procedure for estimation is described in Figure 3. Where flexural toughness is the total energy absorbed by the specimen until the failure occurred, it is also equivalent to the gross area under the load-deflection curve. Flexural toughness indicates pre and post crack ductility of the material. Determining the toughness indices, residual strength factors, and first-crack strength are generally used to compare the behavior of the different kinds of fibers used in concrete. These parameters are used for optimizing the mix proportion of high-performance fiber-reinforced concrete. They are also used for assessing the quality of structural concrete $[29,30,33]$.

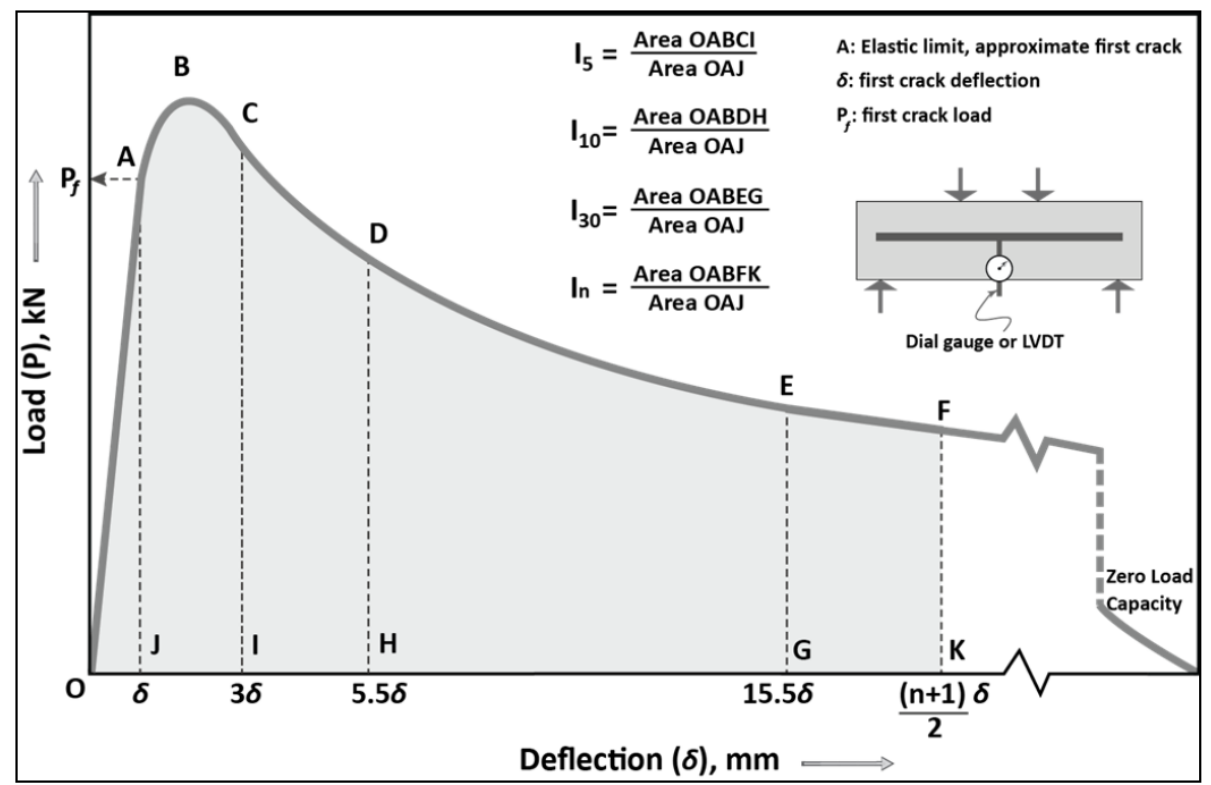

Figure 3. Definition of Toughness Indices (load-deflection curve) according to ASTM C1018 [33,34]. 


\section{Results and Discussion}

\subsection{Effects of Fibers on the Workability (Slump) of Concrete}

As described in the literature, the addition of fibers to concrete reduces its workability $[14,18]$. It is a general practice for achieving a concrete's required workability; an appropriate superplasticizer dose is added. The same approach was followed in this study to acquire the desired workability of the concrete. Figure 4 shows the amount of superplasticizer added to obtain a targeted slump value between $90-110 \mathrm{~mm}$. The water to cementitious material ratio was kept constant at 0.4. It is well established [34] that the addition of fly ash increases the workability of concrete. Therefore, the control mix containing fly ash (CF) included a lower dosage of superplasticizer $(0.25 \%)$ than that added to the $100 \%$ cement mix $(\mathrm{CM})$, which was $0.35 \%$ for obtaining the targeted slump of concrete. However, the fly ash concrete containing fibers required a higher dose of superplasticizer (SP) for achieving the targeted value of slump. For concrete mixes containing $0.3 \%$ volume fraction of PVA, a dosage of $0.3 \% \mathrm{SP}$ was added. With the same volumetric fraction of CSS fibers, the dosage of SP was increased to $0.5 \%$. In all such cases, the addition of SP dosage did reduce the compressive strength value. The compressive strength results are discussed in the next section. The analysis of the fibers' effects on concrete workability showed that CCS fibers caused a substantial reduction in concrete workability than did the PVA fibers. CCS fibers required $0.5 \%$ content of SP dose, whereas PVA fibers needed only $0.35 \%$ for achieving the desired slump of $90-110 \mathrm{~mm}$.

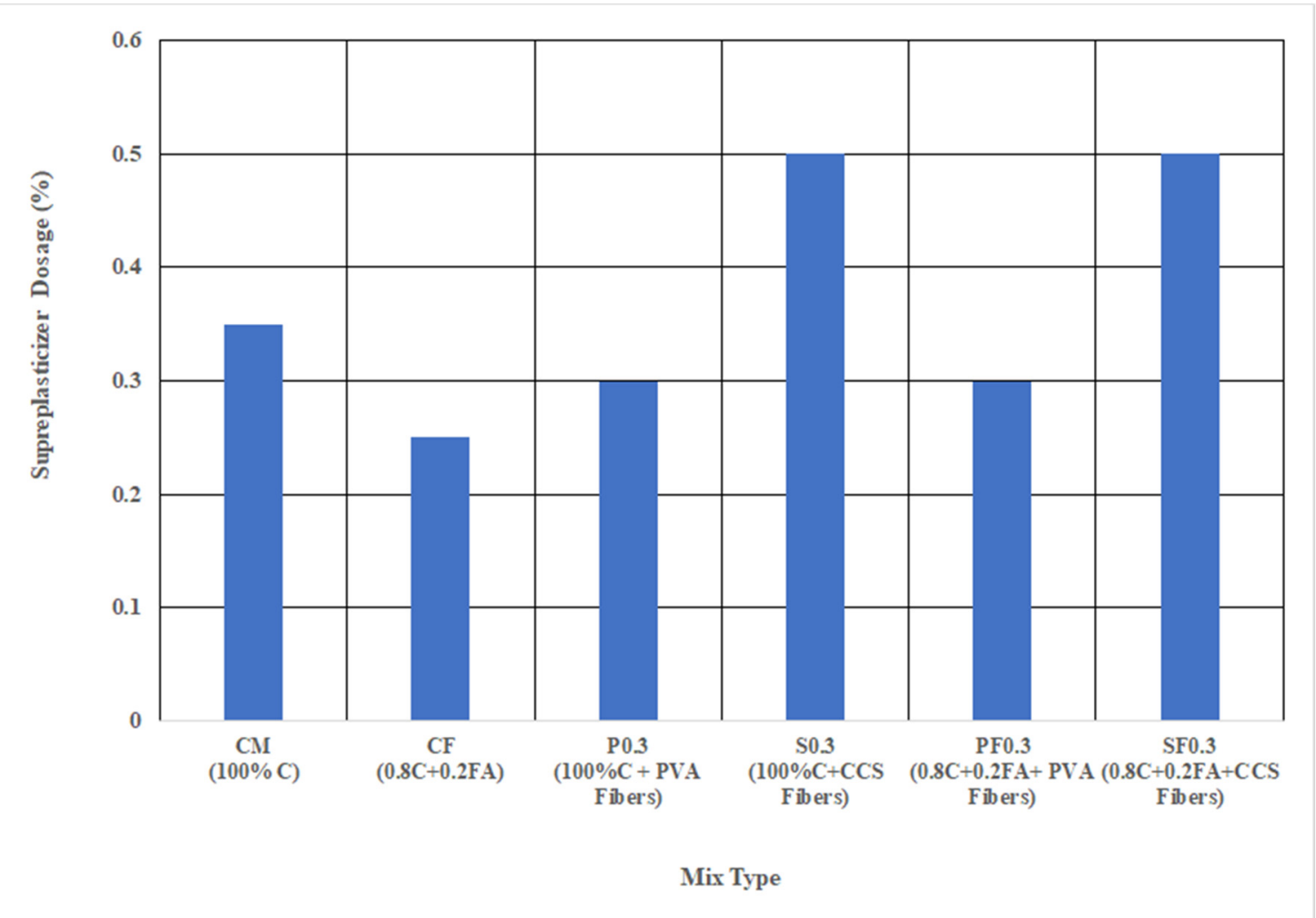

Figure 4. Superplasticizer dosage for achieving $90-110 \mathrm{~mm}$ slump in different concrete mixes. (Note: $\mathrm{C}$ is cement, FA is fly ash).

\subsection{Effects of Fibers and Fly Ash Content on the Compressive Strength of Concrete}

Figure 5 illustrates the compressive strength development of different concrete mixes determined at $3,7,28$, and 56 days of curing. Figure 5 clearly distinguishes the effects of $0.3 \%$ volume fraction of CCS and PVA fibers on the compressive strength of $100 \%$ cement concrete and concrete blended with $20 \%$ fly ash content. The compressive strength of the control mix (CM), containing 100\% cement, was considered as the reference value. 
Therefore, the compressive strength of all other mixes was assessed with the reference value. For the control mix (CM), the reference value at every age of curing is taken as one; all other values of compressive strength were divided by the mix's compressive strength, CM, and the strength efficiency index (SI). The same concept was discussed by Noushini et al. [24] for comparing the efficiency of different concrete mixes. Table 3 shows the SI value determined for various concrete mixtures in this study. The effects of the type of fibers and the fly ash content were considered the research variables. Some research studies showed that increasing the coarse aggregates' size up to a specific limit also increased the compressive strength [35]. Noushini et al. [24] used $12 \mathrm{~mm}$ and $18 \mathrm{~mm}$ long PVA fibers, and they discussed that the long fibers were able to connect and tie together the coarse aggregates in concrete. Results showed that the addition of $20 \%$ fly ash caused a slight delay in compressive strength development. The concrete mixes containing fly ash suffered a loss of strength between $15 \%$ and $35 \%$ at 3 days and 7 days compared to the reference value. A $0.3 \%$ volume fraction of CSS fibers caused positive effects on the compressive strength compared to the control mix with fly ash (CF), which had a $6 \%$ higher strength at 3 days and was $9 \%$ higher at 7 days. At 56 days, fly ash concrete containing CSS fibers and $0.3 \mathrm{SF}$, showed an $18 \%$ higher strength than the reference mix CM and $16 \%$ higher than the CF mix.

Table 3. Compressive Strength (Cube) of all Concrete Mixes.

\begin{tabular}{ccccccccc}
\hline & \multicolumn{6}{c}{ Compressive Strength, $f_{c u}$ (MPa) and Strength Efficiency Index (SI) } \\
\cline { 2 - 9 } Mix ID & $f_{c u}$ & SI & $f_{c u}$ & SI & $f_{c u}$ & SI & $f_{c u}$ & SI \\
\cline { 2 - 9 } & \multicolumn{2}{c}{ 3 Days } & \multicolumn{2}{c}{ 7 Days } & \multicolumn{2}{c}{ 28 Days } & \multicolumn{2}{c}{ 56 Days } \\
\hline CM & 54.14 & 1.00 & 60.45 & 1.00 & 66.77 & 1.00 & 70.88 & 1.00 \\
P0.3 & 54.25 & 1.00 & 60.45 & 1.00 & 69.00 & 1.03 & 73.61 & 1.04 \\
S0.3 & 58.86 & 1.09 & 65.81 & 1.09 & 72.60 & 1.09 & 78.28 & 1.10 \\
CF & 42.94 & 0.79 & 50.10 & 0.83 & 65.97 & 0.99 & 72.00 & 1.02 \\
PF0.3 & 35.38 & 0.65 & 55.62 & 0.92 & 64.00 & 0.96 & 74.50 & 1.05 \\
SF0.3 & 46.22 & 0.85 & 55.37 & 0.92 & 69.32 & 1.04 & 83.57 & 1.18 \\
\hline
\end{tabular}

NOTE: Strength Efficiency Index (SI) $=$ Ratio of the $f_{c u}$ of concrete mix with the $f_{c u}$ of the mix CM.

Compared to the CCS fibers, PVA fibers in $100 \%$ cement concrete showed the same value of compressive strength as in the control mix $(\mathrm{CM})$ at 3 and 7 days. They showed a slight increase in strength at the 28 and 56 days. Whereas tha PVA fibers in fly ash concrete showed a reduction in compressive strength of $6 \%$ at 3 days compared to the control mix, $(\mathrm{CF})$ and a $35 \%$ reduction in strength of the reference mix (CM). However, at 7 days and later, PVA fibers showed an increase in strength between $4 \%$ and $7 \%$ compared to the control mix (CF). In general, the addition of a small volume fraction of $0.3 \%$ of CCS and PVA fibers did not show adverse effects on strength at 28 and 56 days of curing.

\subsection{Effects of Fibers on Tensile and Flexural Strength}

The principal reason for developing fiber reinforced concrete (FRC), was to enhance the tensile and flexural strength and improve concrete post-cracking behavior. Figure 6 shows the split tensile strength and the flexural strength of various concrete mixes measured at 28 days of curing. In analyzing the fiber's performance, results were compared to the reference mix (CM) and the strength efficiency index. SI was calculated, and is tabulated in Table 4. It was observed that the addition of $0.3 \%$ volume fraction of CCS and PVA fibers increased the split tensile and flexural strength by about $7 \%$ in $100 \%$ cement concrete and up to $25 \%$ in the fly ash based concrete, which is a significant improvement. As highlighted in the literature, unlike compression strength, fibers make a complex network of concrete matrices and maintain the mix's integrity [36]. It is stated that longer fibers contribute to improving a concrete's flexure properties [37]. Both types of fibers, CCS and PVA, possessed similar aspect ratios of 100 and 90, respectively; therefore, they showed more or less similar tensile and flexural strength values. Because the flexural strength of concrete 
depends on its tensile strength, Figure 7 shows a linear correlation between tensile strength, $f_{t}$, and flexural strength, $f_{f l}$, given in the following Equation (1).

$$
f_{f l}=1.3349 f_{t}-1.2298
$$

The literature has indicated that the flexural strength of fiber reinforced concrete is usually related to the ultimate compressive strength of the concrete; $f_{c u}$ as $f_{f l}=(0.62$ to 0.83$) \sqrt{f_{c u}}[29,30]$. Figure 8 shows the correlation between the flexural strength and the ultimate compressive strength, and the following correlation was obtained:

$$
f_{f l}=0.6641 \sqrt{f_{c u}}
$$

Equation (2), obtained in this research study, is stated above and presented in the literature [30-32].

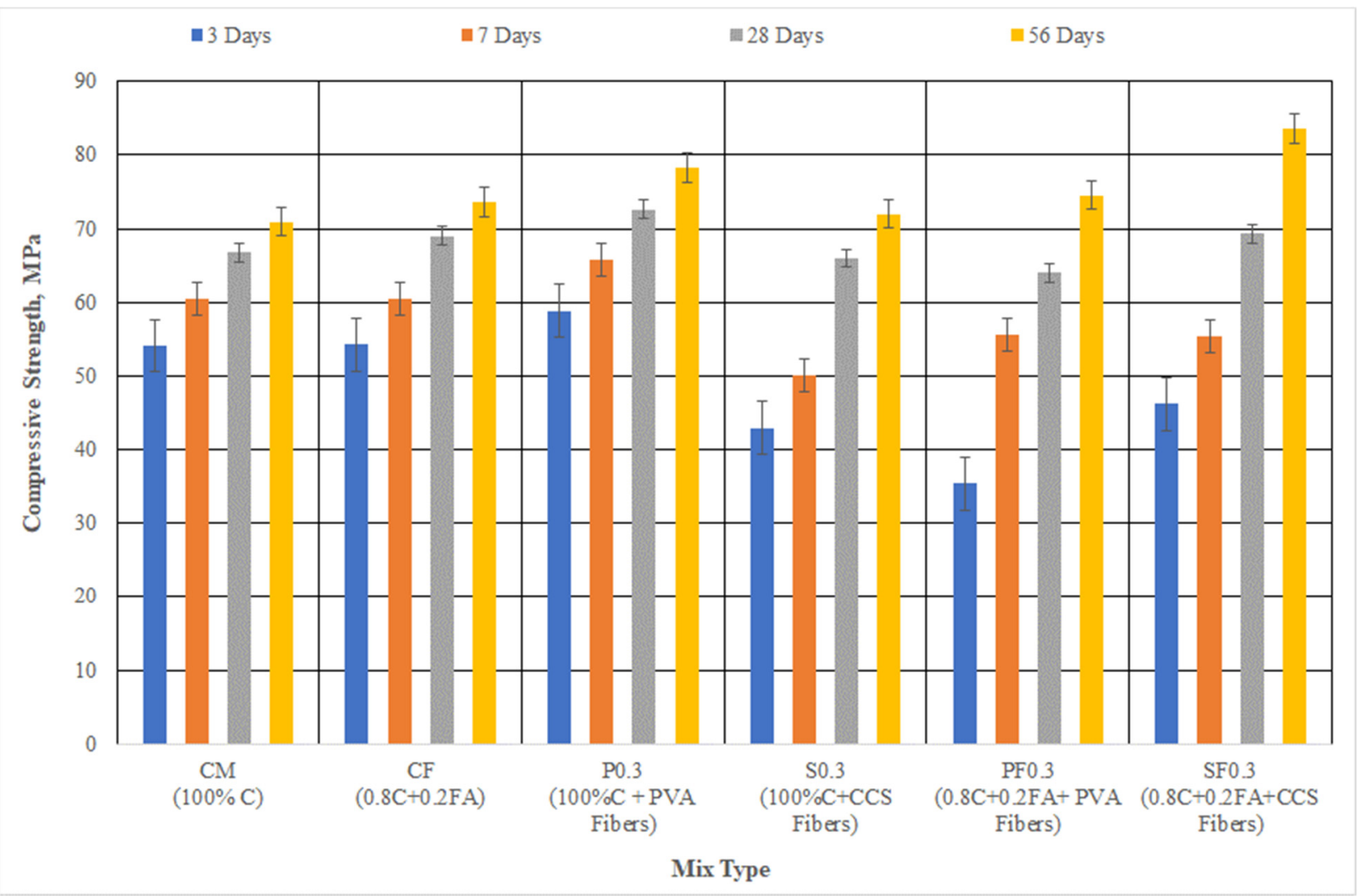

Figure 5. Compressive strength development in different concrete mixes at different ages.

Table 4. Split tensile and flexure strength of concrete mixes determined at 28 days.

\begin{tabular}{ccccc}
\hline \multirow{2}{*}{ Mix ID } & \multicolumn{2}{c}{ Tensile Strength, $f_{t}$} & \multicolumn{2}{c}{ Flexural Strength, $f_{f l}$} \\
\cline { 2 - 5 } & MPa & $\begin{array}{c}\text { Strength Index } \\
\text { (SI) }\end{array}$ & MPa & SI \\
\hline CM & 4.72 & 1.00 & 5.21 & 1.00 \\
P0.3 & 5.08 & 1.08 & 5.5 & 1.06 \\
S0.3 & 5.05 & 1.07 & 5.5 & 1.06 \\
CF & 4.02 & 0.85 & 4.08 & 0.78 \\
PF0.3 & 5.19 & 1.10 & 5.52 & 1.06 \\
SF0.3 & 5.14 & 1.09 & 5.79 & 1.11 \\
\hline
\end{tabular}




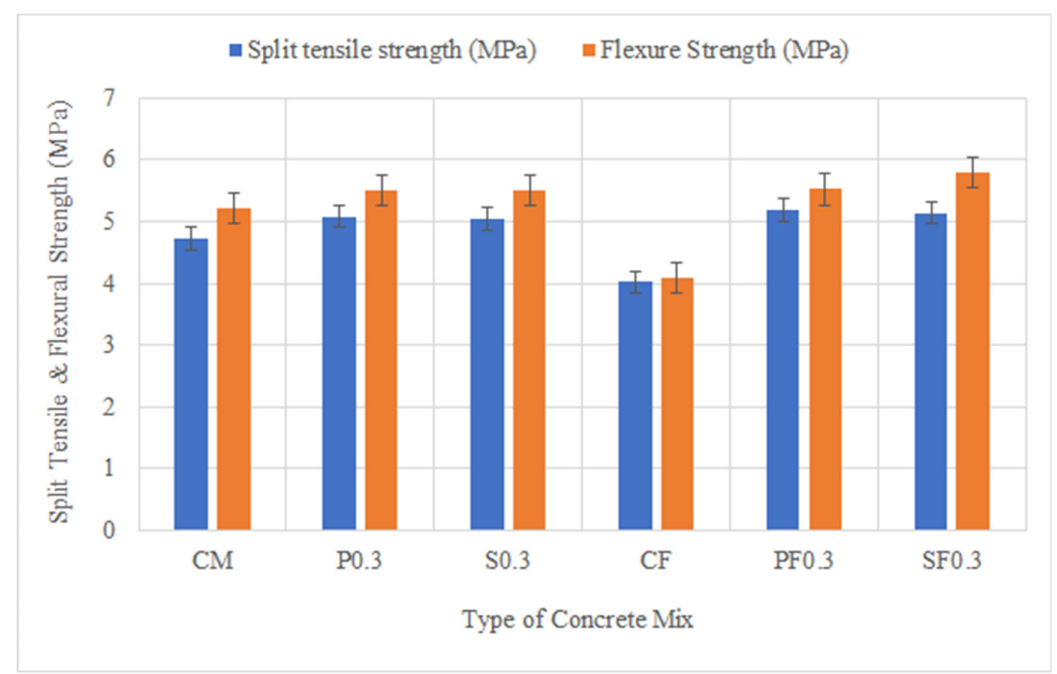

Figure 6. Split Tensile and Flexural strength of different concrete mixes measured at 28 days.

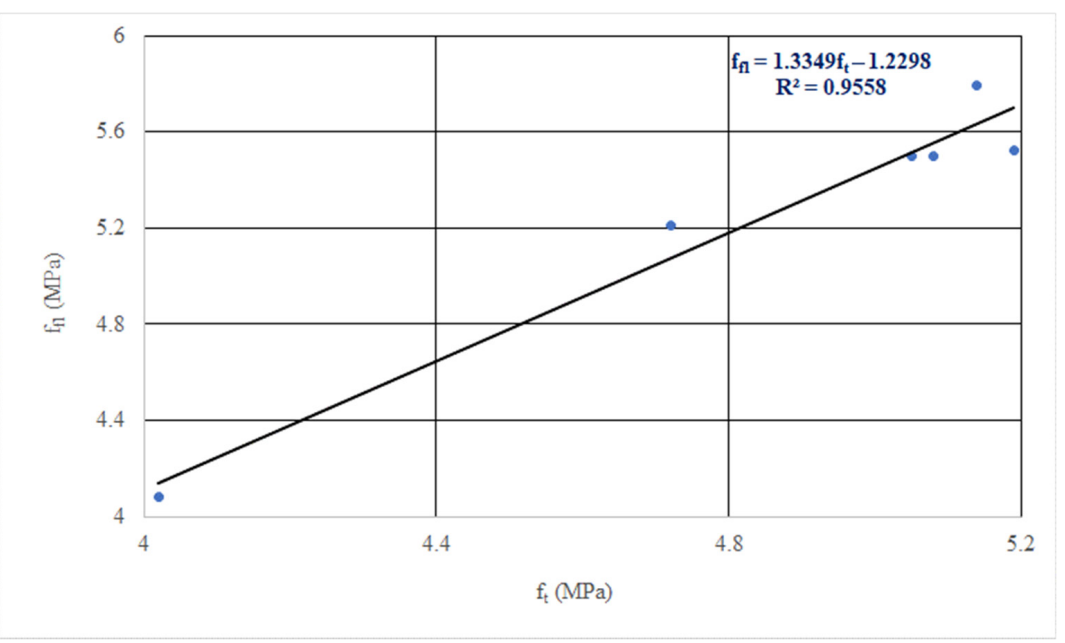

Figure 7. Correlation between split tensile strength, $f_{t}$, and flexural strength, $f_{f l}$.

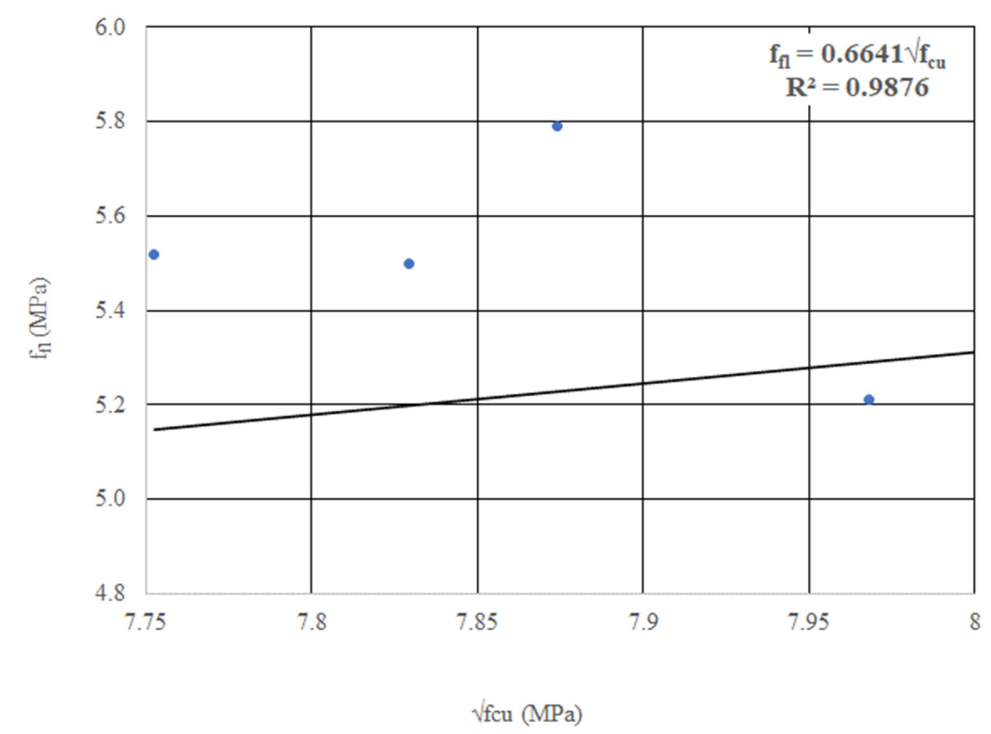

Figure 8. Correlation between compressive strength, $f_{c u}$, and flexural strength, $f_{f l}$. 


\subsection{Flexural and First-Crack Toughness, Indicies, and Residual Strength Factor}

Table 5 contains the estimated values of flexural toughness parameters, indices ( $\mathrm{I}_{5}, \mathrm{I}_{10}$, and $\left.I_{20}\right)$, residual strength factors $\left(R_{5,10}\right.$ and $\left.R_{20,10}\right)$, and deflection for all concrete mixes. It can be observed that the addition of fibers into concrete had significant effects on the first crack toughness, $F T_{f c}$. In the first set of $100 \%$ cement concrete, PVA fibers increased $F T_{f c}$, by $13 \%$ and the CCS fibers increased it by up to $41 \%$ compared the control mix (CM). In the fly ash concrete, PVA fibers enhanced it by $41 \%$ and CCS fibers increased it by $57 \%$ compared to the control mix (FC). This is a substantial improvement in the first crack strength of concrete. The flexural toughness (FT), which was calculated at the failure conditions, showed a significant enhancement with fiber addition. In 100\% cement concrete, PVA and CCS fibers enhanced the FT value 1.8 times and 3.6 times, respectively, compared to that of the mix CM. The flexural toughness ratio and the first crack toughness $(F T / F T f C)$ indicate the concrete's ductility. As shown in Table 5, the $F T / F T_{f c}$ ratio of the control mixes, $C M$ and $C F$, was obtained as 1.3 and 1.26, respectively. For PVA fibers, $F T / F T_{f c}$ was obtained as 2.05 and 1.91. For CCS fibers, it was determined as 3.31 and 2.21, indicating a significant enhancement in the ductility with fiber addition. Figure 9 shows a correlation between the flexural strength, $f_{f l}$, flexural toughness, $F T$, and the first crack toughness, $F T_{f c}$. The following Equations (3) and (4) were obtained:

$$
\begin{aligned}
& F T_{f c}=2.4515\left(f_{f l}\right)^{2}-22.275 f_{f l}+55.38 \\
& F T=8.9728\left(f_{f l}\right)^{2}-80.692 f_{f l}+186.42
\end{aligned}
$$

Figure 10 shows the relationship between first crack strength, $F T_{f c}$, and flexural toughness, FT; a power correlation was obtained as:

$$
F T=0.0955\left(F T_{f_{c}}\right)^{2.5696}
$$

The first index, $I_{5}$, is the ratio of strain energy calculated at $3 \delta$ to the elastic strain energy calculated at $\delta$ (the deformation at first crack). The region from $\delta$ to $3 \delta$ is transitionary when material behavior shifts from elastic to plastic. CCS fibers showed an $\mathrm{I}_{5}$ value of 2.45 in OPC concrete, indicating high resilience of the matrix after the first crack appeared. In fly ash concrete, it was calculated as 1.84. PVA fibers showed an $\mathrm{I}_{5}$ value of 1.82 and 1.59 in OPC and fly ash concrete, respectively. The indices $\mathrm{I}_{10}$ and $\mathrm{I}_{20}$ indicate the matrix's plastic flow behavior calculated at $5.5 \delta$ and $10.5 \delta$, respectively. CCS fibers showed $\mathrm{I}_{20}$ values as 3.33 and 2.21 in OPC and fly ash concrete, respectively. PVA fibers showed an $\mathrm{I}_{20}$ value of 2.05 and 1.91 in OPC and fly ash concrete. The high values of indices shown by CCS fibers could be the reason for the high tensile strength $(2300 \mathrm{MPa})$ compared to PVA fibers. The tensile strength was $1000 \mathrm{MPa}$. In general, the addition of fibers has reasonably improved the plastic flow behavior of the composite.

As shown in Table 5, residual strength factor, $R_{5,10}$, for PVA fibers in $100 \%$ cement and fly ash concrete was obtained as 4.03 and 4.84 , respectively. Similarly, $\mathrm{R}_{5,10}$ for CCS fibers in $100 \%$ cement concrete and the fly ash concrete was determined as 11.93 and 6.77, respectively. The residual strength factor represents the strength retained in the structural member after the first crack onset. A high value of the factor, $R$, indicates the top performance of concrete. In this case, a value of four and above means that the concrete mixes with these fibers can display appropriate plastic behavior. 


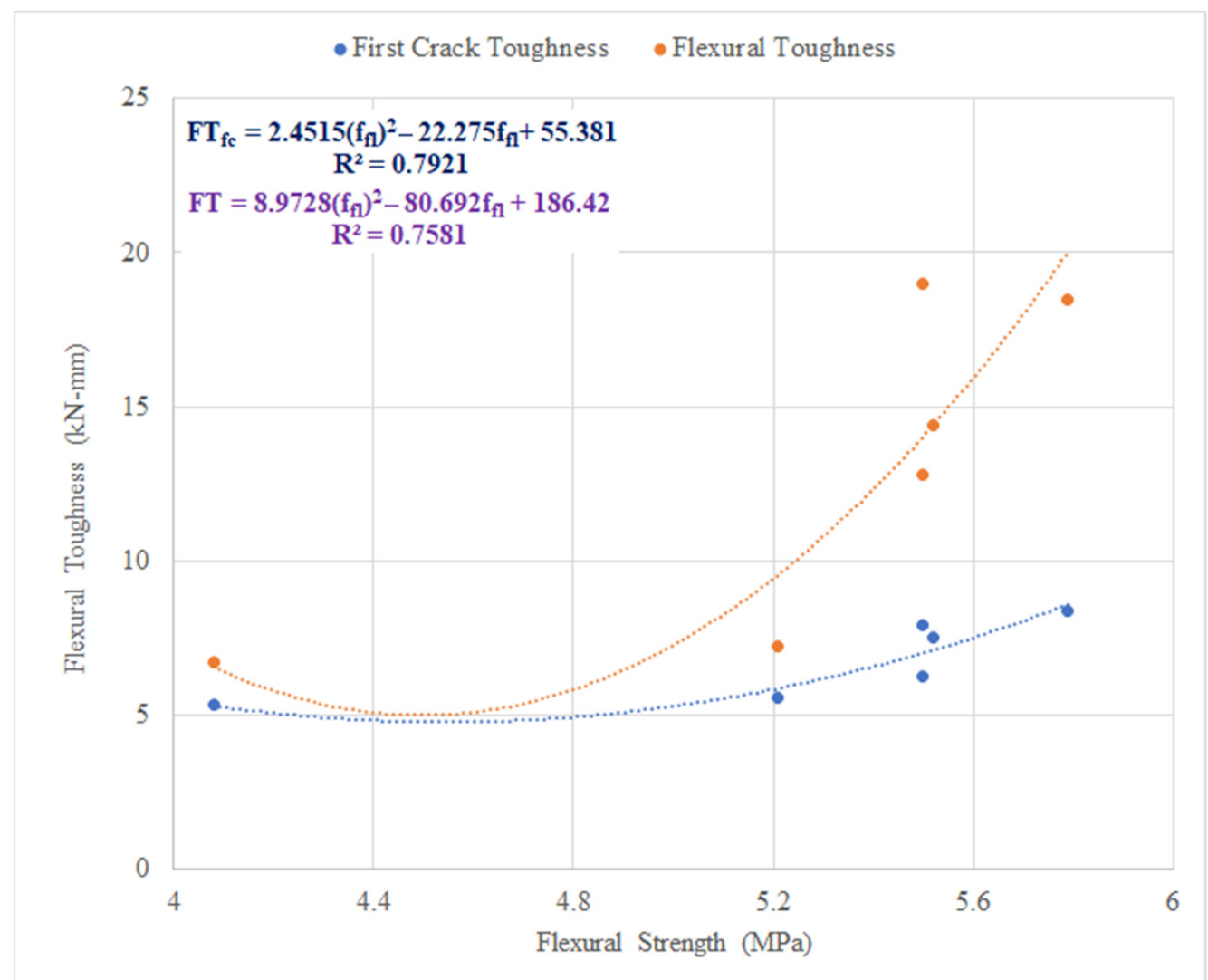

Figure 9. Correlation between flexural strength, $f_{f l}$, and the flexural toughness at first crack, $F T_{f c}$, and ultimate conditions, $F T$.

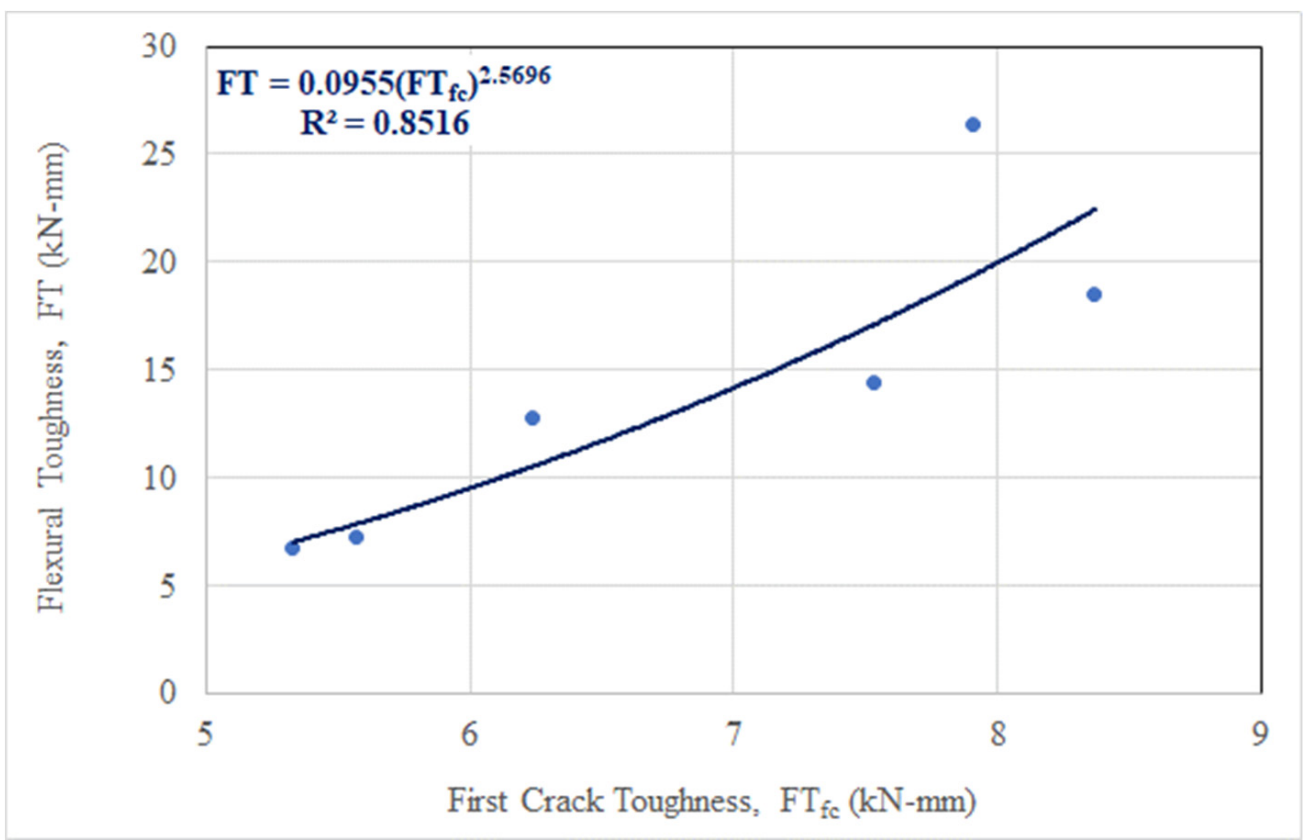

Figure 10. Correlation between First-Crack Toughness and Flexural Toughness. 
Table 5. Post cracking characteristics of concrete, determined according to ASTM1018 [30].

\begin{tabular}{|c|c|c|c|c|c|c|c|c|}
\hline \multirow{2}{*}{ Mix Type } & \multirow{2}{*}{$\begin{array}{l}\text { Toughness at First } \\
\text { Crack, } F T_{f c}(\mathrm{kN}-\mathrm{mm})\end{array}$} & \multicolumn{3}{|c|}{ Toughness Index } & \multirow{2}{*}{$\begin{array}{l}\text { Flexural Toughness, } F T \\
\qquad(\mathrm{kN}-\mathrm{mm})\end{array}$} & \multicolumn{2}{|c|}{$\begin{array}{c}\text { Residual Strength } \\
\text { Factor }\end{array}$} & \multirow{2}{*}{$\begin{array}{l}\text { Deflection, } \\
\delta(\mathrm{mm})\end{array}$} \\
\hline & & $\mathbf{I}_{5}$ & $I_{10}$ & $I_{20}$ & & $\mathbf{R}_{5,10}$ & $\mathbf{R}_{20,10}$ & \\
\hline $\mathrm{CM}$ & 5.57 & 1.3 & 1.3 & 1.3 & 7.23 & 0 & $0 . ` 00$ & 1.34 \\
\hline P0.3 & 6.24 & 1.82 & 2.02 & 2.05 & 12.82 & 4.03 & 0.34 & 7.2 \\
\hline S0.3 & 7.91 & 2.45 & 3.04 & 3.33 & 26.38 & 11.93 & 2.86 & 15.5 \\
\hline CF & 5.33 & 1.26 & 1.26 & 1.26 & 6.72 & 0 & 0 & 1.46 \\
\hline PF0.3 & 7.53 & 1.59 & 1.84 & 1.91 & 14.38 & 4.84 & 0.73 & 12.6 \\
\hline SF0.3 & 8.37 & 1.84 & 2.18 & 2.21 & 18.47 & 6.77 & 0.24 & 12 \\
\hline
\end{tabular}

\subsection{Elastic Modulus and Ductility Index}

Elastic modulus is one of the primary parameters for the study of the elastic deformation of concrete. Elastic modulus is the ratio between yield stress and yield strain. In concrete, the stress-strain curve until yield is not linear. It is not easy to estimate the modulus of elasticity by calculating the yield stress and strain ratio. Codes and standards have recommended an approach based on estimating the secant modulus. In the method described in ASTM C469/C469M and BS EN1992-1 [38], the secant modulus is the gradient of the line joining the origin with a point on the stress-strain curve as it crosses at $40 \%$ of the ultimate strength. In this research, the modulus of elasticity was estimated according to the procedure described in BS EN 1992-1 [38]. A $100 \mathrm{~mm}$ diameter and $200 \mathrm{~mm}$ long concrete cylinder was used. A strain gauge attached to the cylinder monitored the strain with the continuous increment in load.

Table 6 contains the ultimate stress-strain data obtained for all concrete mixes. Figure 9 shows the secant modulus estimate's value according to BS EN 1992 using the stress-strain results shown in Table 6. The addition of PVA fibers significantly enhanced the modulus of elasticity of $100 \%$ cement concrete, which was obtained as $47.6 \mathrm{GPa}, 40 \%$ higher than that of the control mix (CM). In comparison, CCS fibers caused an increase in secant modulus to slightly more than $10 \%$ than the control mix (CM). For fly ash-based concrete, PVA and CCS fibers increased the secant modulus by $8 \%$ and $6 \%$, respectively, compared to the control mix (CF). Another critical property of FRC, the ductility index, can also be determined from the stress-strain curve by dividing the ultimate strain and yield strain $[39,40]$. Table 6 also contains the ductility index calculated for all mixes. With the addition of PVA and CCS fibers, the ductility index (dI) of $100 \%$ cement concrete was increased by $25 \%$ and $87 \%$, respectively, compared to the CM. In the fly ash concrete, PVA and CCS fibers enhanced ductility to $37 \%$ and $91 \%$ compared to the CF.

Table 6. Modulus of elasticity (E), and the ductility index of concrete determined according to BS EN 192-2-2 [34].

\begin{tabular}{|c|c|c|c|c|c|c|}
\hline Mix ID & $\begin{array}{c}\text { Ultimate Stress, } \\
\qquad \sigma_{u}(\mathrm{MPa})\end{array}$ & $\begin{array}{c}\text { Ultimate Strain, } \\
\varepsilon_{u}(\%)\end{array}$ & $\begin{array}{c}\sigma_{40}=0.4 \sigma_{u} \\
(\mathrm{MPa})\end{array}$ & Strain at $\underset{(\%)}{\sigma_{40},} \varepsilon_{40}$ & $\begin{array}{l}\text { Secant Modulus } \\
\left(E_{40}=\frac{\sigma_{40}}{\varepsilon_{40}}\right) \text { GPa }\end{array}$ & Ductility Index $\left(\frac{\sigma_{u}}{\sigma_{40}}\right)$ \\
\hline $\mathrm{CM}$ & 63.49 & 1900 & 25.4 & 747 & 34 & 2.54 \\
\hline P0.3 & 61.3 & 1600 & 24.52 & 515 & 47.61 & 3.11 \\
\hline SO.3 & 66 & 3350 & 26.4 & 705 & 37.45 & 4.75 \\
\hline $\mathrm{CF}$ & 64 & 1940 & 25.6 & 790 & 32.41 & 2.46 \\
\hline PF0.3 & 60.1 & 2300 & 24.04 & 686 & 35.04 & 3.35 \\
\hline SF0.3 & 62 & 3400 & 24.8 & 720 & 34.44 & 4.72 \\
\hline
\end{tabular}

\section{Conclusions}

For all experimental work, the following conclusion can be drawn:

Inclusion of low volume fraction $(0.3 \%$ ) of short (18 to $20 \mathrm{~mm}$ long) copper coated steel, CCS, and PVA fibers in $100 \%$ cement $/ 20 \%$ fly ash concrete enhanced the mechanical properties. The effects were clearly seen in an improvement in the split tensile and flexural strength; they were enhanced by more than $10 \%$ compared to the control mixes CM and 
CF. A valid correlation (within the specified range, as discussed in ASTM C1018) between the compressive strength and the flexural strength was obtained.

The fundamental reason for reinforcing concrete with short, randomly oriented fibers is to improve the load-carrying capacity and energy absorption capability after the onset of the first crack. PVA and CCS fibers increased the first crack toughness by more than $40 \%$ compared to the control mixes and increased the flexural toughness to 1.8 and 3.6 times that of the control mixes' FT. The fibers also enhanced the toughness indices $\mathrm{I}_{5}, \mathrm{I}_{10}$, and $\mathrm{I}_{20}$ and the residual strength factors. These indices indicate the performance of concrete in the plastic region.

Modulus of elasticity is an essential characteristic of concrete for controlling the deformation behavior of the structural members. The secant modulus of PVA and CCS reinforced concrete was obtained between $35 \mathrm{Gpa}$ and $47 \mathrm{Gpa}$, which could reduce the structural members' size. The fibers also improved the ductility of the concrete by $22-91 \%$, which could help avoid a structural collapse in abnormal loading conditions.

Author Contributions: A.J. conducted the experimental analysis, data collection, and analysis. L.H. reviewed the data and wrote the draft manuscript. N.S. supervised the research activities and vetted and corrected the analysis and the manuscript. All authors have read and agreed to the published version of the manuscript.

Funding: The authors feel grateful to extend their gratitude to the Universiti Teknologi PETRONAS to offer financial support for this research. A research grant entitled YUTP under research grant number 015LC0-155 was awarded to the authors.

Informed Consent Statement: Not applicable.

Conflicts of Interest: The authors declare no conflict of interest.

\section{References}

1. Gettu, M.E.; Bazant, R.; Karr, Z.P. Fracture Properties and Brittleness of High Strength Concrete. ACI J. Mater. 1990, 87, 608-618.

2. Kodur, V. Fire performance of high-strength concrete structural members. In Construction Technology Updates (NRC-CNRC); National Research Concil of Canada: Ottawa, ON, Canada, 1999; p. 4.

3. Kosa, K.; Naaman, A.E. Corrosion of Steel Fiber Reinforced Concrete. ACI Mater. J. 1990, 87, $27-37$.

4. Görander, N.; Halldén, C. Crack Width Profiles for Fibre-Reinforced Concrete Elements with Conventional Reinforcement; Chalmers University of Technology: Gothenburg, Sweden, 2015.

5. Abdul-Ahad, R.B.; Aziz, O.Q. Flexural strength of reinforced concrete T-beams with steel fibers. Cem. Concr. Compos. 1999, 21, 263-268. [CrossRef]

6. Hooton, R.; Khaloo, A.; Kim, N. Mechanical Properties of Normal to High-Strength Steel Fiber-Reinforced Concrete. Cem. Concr. Aggreg. 1996, 18, 92. [CrossRef]

7. Song, P.S.; Hwang, S. Mechanical properties of high-strength steel fiber-reinforced concrete. Constr. Build. Mater. 2004, 18, 669-673. [CrossRef]

8. Gherman, O.E.; Constantinescu, H.; Gherman, M.C. Mechanical Properties of High Strength Steel Fiber Reinforced Con-crete. In Proceedings of the 16th International Multidisciplinary Scientific GeoConference 2016, Albena, Bulgaria, 30 June-6 July 2016; ProQuest: Ann Arbor, MI, USA, 2016.

9. Balouch, S.U.; Forth, J.P.; Granju, J.-L. Surface corrosion of steel fiber reinforced concrete. Cem. Concr. Res. 2010, 40, 410-414. [CrossRef]

10. Vairagade, V.S.; Kene, K.S. Strength of normal concrete using metallic and synthetic fibers. Procedia Eng. 2013, 51, 132-140. [CrossRef]

11. Ma, Y.-Q. Experimental Study on Mechanical Properties of Steel Fiber Reinforced High-Performance Concrete. Adv. Mater. Res. 2014, 859, 56-59. [CrossRef]

12. Alhozaimy, A.M.; Soroushian, P.; Mirza, F. Mechanical properties of polypropylene fiber reinforced concrete and the effects of pozzolanic materials. Cem. Concr. Compos. 1996, 18, 85-92. [CrossRef]

13. Song, P.S.; Hwang, S.; Sheu, B.C. Strength properties of nylon- and polypropylene-fiber-reinforced concrete. Cem. Concr. Res. 2005, 35, 1546-1550. [CrossRef]

14. Shafiq, N.; Nuruddin, M. Effect of Chopped Basalt Fiber on the Fresh and Hardened Properties of Fly Ash High Strength Concrete. Appl. Mech. Res. 2014, 567, 381-386.

15. Jiang, C.; Fan, K.; Wu, F.; Chen, D. Experimental study on the mechanical properties and microstructure of chopped basalt fiber reinforced concrete. Mater. Des. 2014, 58, 187-193. [CrossRef] 
16. Choi, J.I.; Lee, B.Y. Bonding properties of basalt fiber and strength reduction according to fiber orientation. Materials 2015, 8 , 6719-6727. [PubMed]

17. Fan, F.L.; Xu, J.Y.; Bai, E.L.; He, Q. Experimental Study on Impact-Mechanics Properties of Basalt Fibre Reinforced Concrete. Adv. Mater. Res. 2010, 168-170, 1910-1914.

18. Elshekh, A.E.A.; Shafiq, N.; Nuruddin, M.F.; Fathi, A.; Memom, F.A. An experimental study on the effectiveness of chopped basalt fiber on the fresh and hardened properties of high strength concrete. Res. J. Appl. Sci. Eng. Technol. 2014, 7, 3304-3311.

19. Jalal, A.; Shafiq, N.; Nikbakht, E.; Kumar, R.; Zahid, M. Mechanical Properties of Hybrid Basalt-Polyvinyl Alcohol ( PVA ) Fiber Reinforced Concrete. Key Eng. Mater. 2017, 744, 3-7.

20. Zeng, C.S.; Gong, M.Z.; Gui, M.M.; Guo, X.Q.; Liu, J.X.; Lin, T.X. Influence of Superplasticizer on Anti-Carbonation Property of Concrete. Appl. Mech. Mater. 2012, 204-208, 3790-3794.

21. Mohammed, B.S.; Baharun, M.H.; Nurudinn, M.F.; Erikol, O.P.D.; Murshed, N.A. Mechanical Properties of Engineered Cementitious Composites Mixture. Appl. Mech. Mater. 2014, 567, 428-433. [CrossRef]

22. Li, V.C.; Wang, S. Microstructure variability and macroscopic composite properties of high-performance fiber-reinforced cementitious composites. Probabilistic Eng. Mech. 2006, 21, 201-206. [CrossRef]

23. Hu, W.; Yang, X.G.; Zhou, J.W.; Xing, H.G.; Xiang, J. Experimental research on the mechanical properties of PVA fiber reinforced concrete. Res. J. Appl. Sci. Eng. Technol. 2013, 5, 4563-4567.

24. Noushini, A.; Samali, B.; Vessalas, K. Flexural toughness and ductility characteristics of polyvinyl-alcohol fiber reinforced concrete (PVA-FRC). In Proceedings of the 8th International Conference on Fracture Mechanics of Concrete and Concrete Structures, Toledo, Spain, 15 July 2013; CIMNE: Barcelona, Spain, 2013; pp. 1110-1121.

25. Noushini, A.; Vessalas, K.; Samali, B. Static mechanical properties of polyvinyl alcohol fiber reinforced concrete (PVA-FRC). Mag. Concr. Res. 2014, 66, 1-19. [CrossRef]

26. Cao, M.; Xie, C.; Li, L.; Khan, M. Effect of different PVA and steel fiber length and content on mechanical properties of $\mathrm{CaCO}_{3}$ whisker reinforced cementitious composites. Mater. Construcción 2019, 69, 200. [CrossRef]

27. Yao, W.; Sun, W.; Shi, Z.; Chen, B.; Chen, L.; Feng, J. Blast-resistant Performance of Hybrid Fiber-Reinforced Concrete (HFRC) Panels Subjected to Contact Detonation. Appl. Sci. 2020, 10, 241. [CrossRef]

28. Zahid, M.; Shafiq, N. Effects of Sand/Fly Ash and the Water/Solid Ratio on the Mechanical Properties of Engineered Geopolymer Composite and Mix Design Optimization. Minerals 2020, 10, 333. [CrossRef]

29. ASTM C 1018-02. Standard Test Method for Flexural Toughness and First-Crack Strength of Fiber-Reinforced Concrete; ASTM: West Conshohocken, PA, USA, 1998.

30. Hammad, A.J.; Sldozian, R.J.A. Flexural and Flexural Toughness of Fiber Reinforced Concrete- American Standard Specifications Review. Glob. Res. Dev. J. Eng. 2019, 4.

31. Mudadu, A.; Tiberti, G.; Plizzari, G.A.; Morbi, A. Post-cracking behavior of polypropylene fiber reinforced concrete under bending and uniaxial tensile tests. Struct. Concr. 2019, 20, 1411-1424. [CrossRef]

32. Zahid, M.; Shafiq, N.; Razak, S.N.A.; Tufail, R.F. Investigating the effects of NaOH molarity and the geometry of PVA fibers on the post-cracking and the fracture behavior of engineered geopolymer composite. Constr. Build. Mater. 2020, 265, 120295. [CrossRef]

33. Van CHANH, N. Steel fiber reinforced concrete. Semin. Mater. 2004, 108-116.

34. Yijin, L.; Shiqiong, Z.; Jian, Y.; Yingli, G. The effect of fly ash on the fluidity of cement paste, mortar, and concrete. Proc. Int. Workshop Sustain. Dev. Concr. Technol. 2004, 339-345.

35. Vilane, B.R.T.; Sabelo, N. The Effect of Aggregate Size on the Compressive Strength of Concrete. J. Agric. Sci. Eng. 2016, 2, 66-69.

36. Yu, R.; Bao, H.; Jian, Z.; Jialing, W. Experimental study on splitting tensile strength and acoustic emission characteristics of polypropylene fiber concrete. In Proceedings of the 2011 International Conference on Electric Technology and Civil Engineering (ICETCE), Lushan, China, 22-24 April 2011; IEEE: Piscataway, NJ, USA; pp. 5981-5984.

37. Buratti, N.; Mazzotti, C.; Savoia, M. Post-cracking behavior of steel and macro-synthetic fiber-reinforced concrete. Constr. Build. Mater. 2011, 25, 2713-2722. [CrossRef]

38. BS EN 1992-1-1: 2004-Eurocode 2: Design of Concrete Structures-Part 1-1: General Rules and Rules for Buildings; European Committee for Standardization (CEN): Brussels, Belgium, 2004.

39. Naaman, A.E.; Jeong, S.M. Structural ductility of concret beams pretressed with FRP tendons. In Non-Metallic (FRP) Reinforcement for Concrete Structures: Proceedings of the Second International RILEM Symposium; CRC Press: Boca Raton, FL, USA, 1995; pp. 379-386.

40. Bouzoubaâ, N.; Zhang, M.H.; Malhotra, V.M. Mechanical properties and durability of concrete made with high-volume fly ash blended cements using a coarse fly ash. Cem. Concr. Res. 2001, 31, 1393-1402. [CrossRef] 